\title{
Chapter 21 \\ Strategies to Promote Deep Renovation in Existing Buildings
}

\author{
Cristina Jiménez-Pulido, Ana Jiménez-Rivero, and Justo García-Navarro
}

\begin{abstract}
Existing buildings play a central role in achieving EU climate and energy targets. Consequently, the building sector faces the complex challenge of finding effective solutions to manage both the conservation and renovation of this stock. Given that building energy renovation has the potential to reduce greenhouse gas emissions and achieve EU targets, the European Commission has developed frameworks and regulatory instruments to foster a deep renovation approach. However, progress in achieving the necessary transformation has been slow. The objective of this chapter is to identify strategies and actions that can accelerate the sustainable transformation of the building stock. We focus on the first renovation stage in which it is critical for accurate data to be collected and processed on the state of buildings to improve decision-making processes. By overviewing current policies and instruments, and new technologies and tools applicable to existing buildings, we explore open challenges and room for improvement to fulfil their potential. In this study, we have identified upgraded instruments and tools and new benchmarks, resulting in innovative strategies and actions as drivers for a sustainable transformation. From this perspective, we introduce how more ambitious approaches can lead stakeholders to develop strategies and apply actions towards a regenerative built environment.
\end{abstract}

Keywords Existing buildings · Accurate data collection - Assessment tools · Regulatory frameworks · Target-oriented actions $\cdot$ Regenerative approach

C. Jiménez-Pulido $(\bowtie) \cdot$ A. Jiménez-Rivero $\cdot$ J. García-Navarro

Research Group Sustainability in Construction and Industry giSCI-UPM, ETSIAAB,

Universidad Politécnica de Madrid, Madrid, Spain

e-mail: c.jpulido@upm.es; ana.jimenez@upm.es; justo.gnavarro@upm.es 


\subsection{Introduction}

Buildings are central to our lives since we all spend more than $90 \%$ of our time inside them (EuroACE, 2020). How to manage existing buildings more effectively is one of the main challenges we currently face. Considering the role that the built environment must play to curb climate change, this challenge is particularly pressing for Europe, where most cities have been consolidated, that is, no more urban land is available. The starting step is to optimise resources and actions to guarantee building conservation. This needs to be followed by strategies aimed at improving building quality and energy performance. Upgrading the stock is of paramount importance in reducing the energy consumption and greenhouse gas (GHG) emissions of existing buildings, since their operation phase accounts for 70-90\% of their entire impact on the environment (Mahmoud, Zayed, \& Fahmy, 2019). According to the existing literature, one of the current major building management issues is scant knowledge of and information on the building stock (González, Zotano, Swan, Bouillard, \& Elkadi, 2017) and its performance. This lack of transparent and comparable data on the building sector represents a major obstacle in taking the right decisions (González et al., 2017).

As the use of energy in buildings globally is expected to continue to rise under business-as-usual projections (Chalmers, 2014), innovative strategies to manage the built environment should be implemented. Furthermore, innovations applied to existing buildings should go hand in hand with the evolution of the construction industry. Although it is one of the largest industrial employers in the EU (EuroACE, 2020), the construction sector has not been traditionally considered an early adopter of technology. Given that other sectors are making great strides by, among others, using information and communication technologies (ICTs), the construction industry should consider how innovative tools and technologies could support positive changes in its business practices. Technological advances can be applied to foster improved energy performance in the building stock, for instance, or to optimise the renovation design process. Innovation could help the construction industry become more competitive and decarbonise (European Commission, 2018) with a view to an improved built environment.

Improving the built environment requires actions to accelerate a deep renovation of buildings. Comprehensive renovation of the building stock to lower its energy demand is required under the European energy performance of buildings directive (EPBD) (European Commission, 2018). Renovation not only extends the life of buildings but also raises the quality of living and working spaces, thus improving occupant satisfaction and comfort (Wright, 2018). By introducing an optional scheme called the Building Renovation Passport (BRP) to provide a renovation roadmap, the amending EPBD attempts to promote deep renovations and solve some traditional problems detected in building management. The decisions adopted when planning building interventions should be based on a previous diagnosis from reliable technical data to avoid uncertainties; nonetheless, this is not a common practice yet (Kolokotsa, Diakaki, Grigoroudis, Stavrakakis, \& Kalaitzakis, 2009). 
Therefore, appropriate inspections to assess the condition of existing buildings are vitally important in building stock management. Developing tools capable of supplying data of adequate quality and new systems supporting the technical assessment could anticipate the potential impacts existing buildings may have and guide technicians to find optimal solutions.

Innovation applied to building operation and maintenance processes has a clear potential to face the challenge of building stock preservation and improvement. However, there is no universal standard to extend the service life of buildings and, specifically, to increase building stock resilience, which can offer people better living and working conditions (Chalmers, 2014). This can be achieved through a strong benchmark in resilient features. Resilient aspects in buildings can be defined as a building construction that can "respond to change and to create lasting wellbeing for people and place" (Bhamra, 2015), and having the capacity to recover its overall required functionality. To the best of our knowledge, a common strategy to guide the required collection of data is not in place.

Exploiting the data collection of existing buildings successfully requires careful planning and understanding of the data to be mined (Wright, 2018). Neither are standardised systems in place for processing and evaluating the information collected on existing buildings. Some standards and certification systems have been developed, such as LEED (Leadership in Energy and Environmental Design, www. usgbc.org/leed), BREEAM (Building Research Establishment Environmental Assessment Method, www.breeam.com) or DGNB (Deutsche Gesellschaft für Nachhaltiges Bauen, the German Sustainable Building Council, www.dgnb.de), although applying them is voluntary, and their original focus was not on existing buildings. The reality is that existing building assessment tools neither explicitly consider resilient aspects of the building stock nor seek a restorative or regenerative built environment. Restorative buildings are those that can repair social and ecological systems to a healthy state (RESTORE, 2018). Regenerative buildings can go beyond their site boundaries through a positive interaction with their surrounding human and natural systems (Craft, Ding, Prasad, Partridge, \& Else, 2017). By embracing a regenerative paradigm, a renovated building stock would find a balance and co-evolution between social and ecological systems (RESTORE, 2018).

Nevertheless, given the dimensions of the challenge, it requires a holistic and strategic approach to achieve the desired results: an improved and sustainable built environment. Building complexity demands a specific analysis and focused approach (RESTORE, 2020), capable of addressing the current challenge from a variety of perspectives and levels. The objective of this chapter is to identify strategies and actions that can accelerate the regenerative transformation of the building stock. Our analysis focuses mainly on the assessment phase, due to its relevance in ensuring a good decision-making process. We start by providing an overview of the main regulatory instruments and tools applicable to existing buildings. We then reflect on how the processes can be improved to provide the needed accurate data, which is imperative to guide more strategic and effective actions. By assuming that a creative and innovative vision allows us to shift from the resilience of the built environment towards its restoration or even regeneration, our ultimate intention is to 
highlight effective strategies to address current challenges in the building sector and to promote a faster transformation.

\subsection{Toward a Transformation of the Built Environment}

Based on the above, the built environment's current situation can be considered as generally accepted by the stakeholders involved. Experts agree that deep renovations of existing buildings have the potential to effectively reduce GHG emissions and curb climate change. Many stakeholders have already formed a global partnership and are strongly committed to adopting the 2030 Agenda for Sustainable Development that requires taking urgent action on climate change. Cities and existing buildings are elements of critical importance for that purpose. The 2030 Agenda contains 17 Sustainable Development Goals (SDGs) and 169 targets, outlined by United Nations Member States in 2015. Complementary to the SDGs, the Paris Agreement provides overarching regulatory frameworks, which are particularly relevant for the building sector as they target improvements in energy and resource efficiency (European Commission, 2019). Moreover, the European Commission published a roadmap in 2011 for moving to a competitive low-carbon economy in 2050, highlighting that the building sector could make a significant contribution to emission reductions (European Commission, 2011). The potential for cost-effective energy savings is so high that the building sector has become a priority area to meet climate and energy targets (BUILD UP, 2019). Blueprints shared on decarbonising the built environment are, therefore, a key aspect for achieving climate neutrality by 2050 .

Moving forward and achieving those goals involves transforming commitments into standard operating procedures, and estimating the tools and resources required. Consequently, this section is structured into three subsections. Firstly, we examine the current building stock management situation in relation to regulatory instruments. Secondly, we explore the potential of assessment tools and rating systems to assist in building stock transformation. Thirdly, we highlight new technologies that could be applied to achieve targets. By analysing these three aspects, we provide a general picture of the built environment as a first step towards arriving at solutions to transform it sustainably. Some trends and possible actions have been identified from the analysis as better solutions to current problems, keeping the goals in mind.

\subsubsection{Regulatory Instruments: Policies, Plans and Standards}

Existing regulatory instruments in the European geographical context have been analysed. Most cities in Europe share common building conservation, energy inefficiency and quality problems. The European Union (EU) also provides a common regulatory framework that is later applied by Member States (MS). Apart from the 
above-mentioned roadmap, launched in 2011, EU leaders adopted the 2030 climate and energy framework in 2014. In 2019, the EU and all MS adopted the European Green Deal, aligned with global commitments (2030 Agenda for Sustainable Development and the Paris Agreement). Central to the European Green Deal is the launching of the "Renovation Wave" initiative, which aims to promote a faster rate of building renovations, needed to improve energy efficiency and reduce associated GHG emissions. The EU Construction 2020 Strategy has also been defined to increase the sector's competitiveness as it was developed to improve resource efficiency (European Commission, 2016).

The construction sector is a complex industry requiring a set of specific standards and regulations to meet shared goals. Figure 21.1 shows a timeline of key EU regulatory instruments affecting buildings. There is a large body of existing EU policies and measures that tackle emissions and other climate targets across all economic sectors (European Commission, 2011). Some policies also address the particular situation of buildings in terms of their consumption of resources including energy. A few examples are the Renewable Energy Sources (RES) Directive (2009/28), the Waste Framework Directive (2008/98/EC), the Energy Efficiency Directive (EED) (2012/27/EU), and the Energy Performance of Buildings (EPBD) (2010/31/EU). The last two directives are the most relevant for building stock renovation as their requirements play a crucial role in increasing its energy efficiency. The current EPBD sets a clear direction for the full decarbonisation of the European building stock by 2050 and provides tools, such as the BRP, to achieve it (BUILD UP, 2019). Although these regulations have had a positive impact on the energy performance of buildings since they came into force (European Commission, 2019), climate and energy goals are still far from being achieved. Further implementation efforts are, therefore, an urgent task to achieve the sought-after impact on building performance.

Each MS must take their responsibility towards improving the building stock seriously, adapting the targets to their particular situation (EuroACE, 2020) by developing specific plans to apply European regulations. Among other tools, the

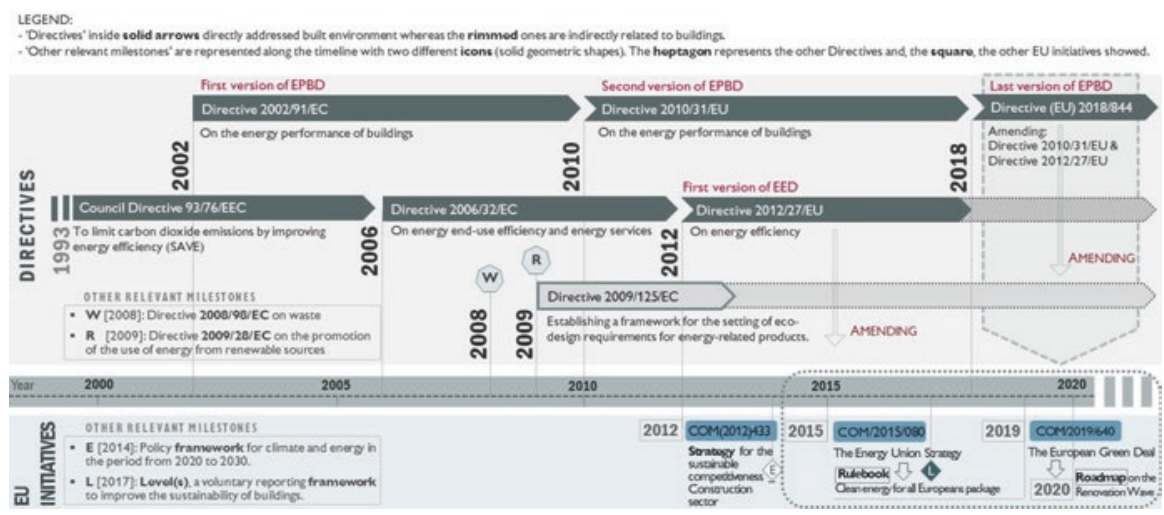

Fig. 21.1 Timeline of key EU regulatory instruments affecting buildings 
EPBD requires all MS to establish a long-term renovation strategy to turn national buildings into a highly energy efficient and decarbonised stock by 2050. Going further, the EPBD encourages MS to facilitate the cost-effective transformation of existing buildings into nearly zero-energy ones. To support that transformation, additional instruments have been launched. For instance, the "Clean energy for all Europeans" package addresses some of the existing regulatory gaps in MS building legislation and tries to create a supporting framework for decarbonising the European building sector.

The complexity of the building sector demands a set of harmonised standards to ensure compliance with regulations and to guarantee a widely acceptable quality of existing buildings (RESTORE, 2020). Therefore, it is crucial to share a common technical language across all MS and to verify compliance with EU requirements and demands (RESTORE, 2020). EN Eurocodes (EN; harmonised technical rules) are a series of ten European Standards that are the reference codes for the design of buildings and civil engineering works. As some of the most used construction standards in Europe, their acceptance by MS and transposition to National Standards are mandatory. Besides EN Eurocodes, standards such as ISO, DIN or BSI are used in several building types. However, significant gaps still need to be addressed in renovation projects, including reliable assessments of the condition and performance of existing buildings. To fill these gaps, the European Commission has developed Level(s), a voluntary reporting framework that provides a common approach for measuring the environmental performance of buildings (Wright, 2018).

An integrated approach to take account of the Directives and standards on existing buildings is seen as necessary (Wright, 2018) and may contribute to achieving EU climate goals. This, together with promoting more ambitious renovation projects, holds the potential to truly guide building stock decarbonisation and thereby reduce its environmental impact and increase its quality. Policies and schemes for sustainable buildings should be clearly linked to the management of existing buildings and their conservation to achieve a more resilient and efficient built environment. By doing that, staged deep renovations could be planned after proper data collection, which is the way to guarantee better building operation management. We have also identified a need to use tools designed to assess the condition and performance of existing buildings through the collected data, together with the development of specific benchmarks and schemes for effective building renovations.

\subsubsection{Data, Assessment Tools and Rating Systems}

As seen above, practitioners and decision-makers need tools that enable them to evaluate existing buildings' condition. This would lead to improved decisionmaking processes on actions to be taken, which should be guided by measures for a more sustainable and resilient built environment. Starting with the diagnosis process when an existing building is inspected, such tools could assist technicians in 
building operation management. It would be advisable for those tools to also be capable of considering the peculiarities of any given existing building, but under clear strategies to support the achievement of ambitious targets related to building stock performance as a whole (Olsson, Malmqvist, \& Glaumann, 2016). Regarding the energy efficiency targets set by policies on buildings and how to meet them, the transparency of the tools to be used should be outlined and applied consistently. This subsection overviews tools currently used to assess existing buildings and to identify gaps and areas for potential improvement. We cover several tool types with a focus on the required collection and processing of data.

Two main aspects of existing buildings need to be improved to achieve the goals established for the built environment: $(a)$ conservation actions to be applied to existing buildings to extend their life span; and $(b)$ energy performance actions. Comprehensive and updated information, together with reliable mechanisms to evaluate these two aspects ( $a$ and $b$ ) would be very helpful to guide the needed building stock renovation. Several database and evaluation tools are used to assess buildings. However, addressing both aspects simultaneously could entail additional benefits for both the built environment and users, such as the improvement of indoor air quality.

High-quality data are needed to conduct proper assessments of existing buildings as a first step towards applying effective actions to improve them. Consequently, the amending EPBD makes explicit reference to building data collection (Article 10) as a necessity before applying outlined measures in renovations aimed at achieving targeted energy savings (European Commission, 2018). MS are currently developing their databases with building performance information. The European regulatory instruments also recommend regular inspections of existing buildings as another useful source of accurate data on them. Therefore, the widespread use of these databases needs to be promoted alongside the development of new mechanisms capable of providing reliable information on the conditions of existing buildings. A more in-depth knowledge of the building stock would strengthen the assessment of existing buildings for a better renovation process, thus contributing to the committed improvement of the built environment.

Regarding currently used assessment tools, EU regulatory instruments include a mandatory one to assess energy performance called the Energy Performance Certificate (EPC). MS have already established EPCs but, according to the EPBD, their transparency needs to be improved. To truly meet the objectives of an energy efficiency policy for buildings, clear energy parameters for calculations need to be applied consistently (European Commission, 2018). In our view, two additional shortcomings can be detected in EPCs: (1) the EPC does not provide information on the building's condition; and (2) the recommendations included as part of the certificate are merely limited to the building's improved energy performance without considering other possible improvements, and application is not mandatory. Concerning the first point, there is not even a mandatory evaluation tool for building condition assessments, shared by all MS (similar to the EPC for energy performance), based on clear standards that have not yet been set. The above-mentioned BRP is an attempt to address this problem, but it is an optional tool that is still being defined. 
Apart from the covered mandatory tools, there are other rating systems for building sustainability evaluation, whose scope is much broader, but they are voluntary. Some of the most used certification systems, such as LEED, BREEAM and DGNB, have also been adapted for renovation purposes. These certification systems have different assessment attributes, evaluation models and ranking scale, so there are noticeable differences between them (Mahmoud et al., 2019). Additionally, many assessment tools addressing sustainability aspects can be found in the literature. Many were developed under funded research projects and also operate under several frameworks (Huovila, Bosch, \& Airaksinen, 2019). Some other tools were developed especially for rating sustainability in existing buildings, such as the one designed by Mahmoud et al. (2019). However, none has currently gained either general or renovation-specific acceptance (Thuvander, Femenías, Mjörnell, \& Meiling, 2012).

In light of the above, responding to the challenges involved in managing existing buildings can accelerate a sustainable transformation of the built environment. One of the main problems encountered in building conservation and renovation is a lack of knowledge of and information on the building stock and its performance (González et al., 2017). Although the body of knowledge is growing, it shows that data availability is still erratic, and that this lack of reliable data is a major obstacle when building sector professionals need to take the right decisions on existing buildings (González et al., 2017) to improve and decarbonise them. While existing mandatory evaluation tools seem partial and incomplete, voluntary ones are complex and often difficult to implement effectively for all existing buildings. Assessing the current state of the buildings after establishing sustainability goals for renovation projects would make the processes more targeted (Nielsen, Jensen, Larsen, \& Nissen, 2016) and the tools more useful. However, only a few of the tools consider the building stock's resilient aspects (e.g. building condition evaluation) and guarantee its adaptation to changes in the economic, physical and social context. Furthermore, considerably fewer tools adopt a more holistic and ambitious approach (e.g. those embracing the regenerative paradigm).

\subsubsection{Innovative Tools and Technology}

From the elements outlined above, we identified gap analysis and data mining as tools that could provide guidance and some recommendations for a positive transformation of the built environment. Moreover, this should be accompanied by innovation to successfully fulfil previously outlined commitments, as suggested in the EPBD. The building sector should take advantage of opportunities, such as the development of new energy efficiency solutions, applicable to existing buildings, or the potential of using tools, such as building information modelling (BIM), to support the management of a building's performance. As further outlined below, not only can innovation make a notable contribution to the improvement of the building stock, but it could also trigger a positive transformation of the entire building sector. 
Starting from accurate data collection, innovation applied to inspection techniques for existing buildings would allow experts to conduct an in-depth study of their condition and the state of conservation of their components. Technical inspections should be used as a source of reliable data. A proper and comprehensive diagnosis would avoid having to adopt building intervention decisions without a thorough analysis of technical data, as decision-making based on a technical report after only a visual inspection is still too common (Bortolini \& Forcada, 2020; Kolokotsa et al., 2009). The development of new inspection technologies, together with the use of tools to process and interpret the data, could play a key role when applied to building operation and maintenance processes. Therefore, new technologies, such as automation and control systems, have a clear potential to preserve and improve the quality of the building stock.

Following the example of other sectors, the construction industry should benefit from the potential of ICTs and other new technologies by developing and applying them to existing buildings. It should also take advantage of the contribution to the construction industry's decarbonisation that can be achieved (European Commission, 2018) and the potential contribution to a better quality of the built environment. Many initiatives use technologies to improve buildings' performance and, even to explore their potential for regenerative design (Sonetti, Naboni, \& Brown, 2018). For instance, the main objective of European projects - such as MOBISTYLE (2016), or InBetween (2017) - is to research and disseminate innovative ICT solutions for energy savings. Therefore, ICT is a prominent tool that could prove suitable for providing necessary reliable information on existing buildings. Ensuring that specific information from those tools is integrated and interlinked provides an opportunity to improve decision-making processes for existing building management and operation, and even renovation.

The most recent amendments to the EPBD suggest going beyond the application of ICT tools, pointing out that the full potential of technical building systems and building automation and control systems can be leveraged for improved energy performance outcomes (EuroACE, 2018). An additional concept, the smartness of buildings, has now emerged and it is closely related to the availability of ICT tools (Wright, 2018). The new concept of 'smart readiness' promotes smart-ready systems and digital solutions applicable in the built environment, for instance, features capable of responding to external conditions or systems allowing occupant-building interactions. Some of the challenges related to the smartness that need to be addressed are to make them reliable, private, and secure, affordable and user-friendly.

Since assessment is highly dependent on good data, the combination of techniques capable of providing appropriate information and innovative tools for better processing of the collected information can increase the capacity to evaluate existing building performance. Many defects in non-structural elements could be solved systemically, thus supporting the feasibility of developing new technologies capable of applying ICT data during the pre-design of renovation projects. New tools should then be connected to existing databases, facility management systems, simulation tools, and BIM models to the extent this is advantageous (Nielsen et al., 2016). 
Ultimately, the development of support tools and procedures ensuring the availability of quality data can anticipate the potential problems of existing buildings and address them in advance.

\subsection{Some Reflections on Innovative Approaches to Move Forward}

Strategic reflection is now needed to move forward because the reality is that the built environment is far from achieving its objectives. Despite the above-described tighter and more ambitious standards, the energy renovation rate in Europe remains around $1 \%$ per year, of which just $12 \%$ are deep renovations (EuroACE, 2020). At this point, it seems advisable to help European cities move from 'business-as-usual' to a 'transformative' mindset by promoting more effective actions on building stock. Since we are facing a complex endeavour, building renovation needs to be addressed from several perspectives and levels, including the revision of current frameworks, optimised data collections, better organised rating systems and interpretation processes.

By applying innovative approaches to conserve and renew the building stock, cutting-edge actions should be tested, and wider benefits must be measured. This needs to coincide with expanding the use of the above-mentioned databases to improve transparency and shared knowledge with a view to developing joint initiatives. More specific, target-oriented and affordable actions to overcome current technical and financial barriers could include streamlining procedures (Wright, 2018). Explicit calculation procedures and ease of use are crucial aspects in the overall sustainability appraisal process (Mahmoud et al., 2019). The use of new technologies such as IT platforms to hold information and link construction agents can also contribute to that end. We must not forget that the strategies need to encompass the challenges of the built environment and cities, thereby considering health and social issues, liveability, sustainability and climate change simultaneously. We believe that these actions can achieve more impact by embracing strategies to promote restorative renovation projects.

To guide the reflections, we focus firstly on gaps and some room for improvement detected in the current tools and systems. Secondly, a brief overview is provided of some pioneering initiatives and cutting-edge actions that could be applied to the building stock to increase its renovation rate and overall quality. 


\subsubsection{Specific Frameworks and Assessment Tools for Existing Buildings}

The main voluntary assessment tools used, along with others found in the literature and developed as part of several research projects, operate with multiple indicator systems. This high number of indicators makes them difficult to implement (Huovila et al., 2019). Indicator systems need to be harmonised and aligned with international commitments (e.g. EPBD aims, or the Sustainable Development Goals, SDGs). The EU is meeting this need by developing the Level(s) Framework, robust indicators based on existing tools and standards to establish a basic common language around sustainable building (Wright, 2018). This task is complex, and it is not yet completely developed. For the sake of simplicity, the framework could be developed to address a range of scenarios with a design based on specific contextual needs and requirements.

The earlier the assessment of existing buildings, the higher the potential to effectively influence their life-cycle performance (Pombo, Rivela, \& Neila, 2016). Therefore, more systematic assessment mechanisms could make a positive contribution to the building stock. However, there is no common protocol to follow during inspections to assess a building's condition. Used as a benchmark for technicians and other stakeholders involved in building management, frameworks and rating systems - focused on specific tasks within the scope of work - could increase the quality of operation and maintenance services. For instance, frameworks developed to guide the needed inspections of existing buildings and diagnose their condition, from the perspective of the built environment targets, would ultimately contribute to improving the results of the renovation works.

The overview of existing instruments that can be applied in building stock transformations is a valuable starting point to address the development of these new frameworks and focused assessment tools. However, more ambitious approaches must also be tested to deal with today's great challenges. For instance, a restorative approach could be used to drive renovation projects with more impact in their surrounding area. More concretely, these kinds of projects could apply to nature-based solutions, such as green roofs and walls providing insulation and shade for buildings. Renovation embracing some restorative measures would contribute to reducing the energy demand, but also to regenerating the city environment (European Commission, 2018). Therefore, by adding restorative solutions to the set of indicators included in new frameworks developed for building management, the sustainable built environment transformation could be accelerated.

When interventions are carried out on existing buildings, the decisions about building materials or constructive system solutions are critical and have a strong impact on existing buildings' adaptability, durability and, consequently, their resilience. Data are crucial for taking good decisions and these should be supported by a reliable assessment of the existing building condition. An appropriate analysis of the state of buildings determines their cohesion in terms of construction together with the safety and serviceability of the structures (Sesana, Rivallain, \& Salvalai, 
2020). Designers need to deal with the diversity of the building stock, varying typologies, age, occupancy, etc., to plan appropriate deep renovations. Their decisions on renovation processes to solve the problems detected depend on obtaining a reliable diagnosis of any degradation processes. Therefore, a systematic assessment based on collected data would enable informed decisions during the renovation process.

If the construction sector wants to fulfil the requirements of the built environment set by EU directives and international regulatory frameworks, innovation and emerging technologies should be employed to improve building stock management. As already mentioned, there are technologies that can be applied to systematise the maintenance process of existing buildings. Indeed, tools in the field of heritage have been recently introduced, for instance, Building Information Modelling for heritage (Heritage-BIM) (Historic England, 2017). Using specific rating systems and new benchmarks, the innovative assessment processes referred to above could then be combined with new technologies to maximise the effectiveness of data collection and interpretation. Then, more comprehensive and relevant data could be achieved by taking advantage of the interoperability of the different database and the capability of the new technologies, provided that the database design is appropriated. Instead of the usual visual inspection assessment, advanced evaluation tools can be used as an example of technology that can provide a good basis. The support of technologies applied to building inspections can improve not only the quality of data collection but also the precision of the diagnosis.

Strategies and tools that enable improved decision-making processes during the assessment stage must be developed to support the achievement of ambitious building stock performance targets (Olsson et al., 2016). From our perspective, this is a good starting point for a more sustainable and resilient built environment. Exhaustive and detailed diagnoses of the condition and performance of existing buildings are needed to design customised interventions as part of ambitious projects. The best suited projects would also enable budget control for retrofit works, one of stakeholders' major concerns, and an important barrier to sustainably transform the built environment. The systematisation of works to solve problems and issues in existing buildings are already generally feasible by applying ICT data to evaluation tools or to the pre-design of renovation projects.

\subsubsection{Strategic Actions on Existing Buildings}

The management of existing buildings should include the combination of technical maintenance and a quality assessment of the entire building, including regular energy audits. Damage or defects in existing buildings can compromise their structural performance, their energy efficiency and indoor air quality. Furthermore, the consequences of those defects are not merely technical, as they can also cause users to suffer health problems, and waste resources and energy. BRP could become an appropriate instrument to address existing building management in the holistic manner suggested, since this instrument can gather all relevant building information 
in one place, along with a long-term roadmap to plan deep renovations. Indeed, the European Green Deal relies on the use of individual BRPs as a central tool to make the EU Renovation Wave a success (EuroACE, 2020). However, since BRP is voluntary, its successful implementation depends on the involvement of all stakeholders and strategical actions to boost its use.

One possible strategic action that can be taken to extend gradually the use of the BRP is its implementation only in particular building elements instead of the full system. BRPs could be divided into minor parts because the building elements have their own particular features and dynamics. For instance, the façade is the most challenging element of buildings since it concentrates many of their problems across their lifetime; therefore, it deserves specific attention. Furthermore, as a connecting element between the interior and exterior, façades exert a key influence on two aspects: the energy efficiency of buildings and the comfort level of their spaces. Considering that there are 60 billion square meters of façade surfaces in MS (ENVISION, 2015), a specific chapter on façades of BRPs could also be a strategic instrument to address both aspects at the same time, and be used as a trigger point. After a proper characterisation of the building's façade, this instrument could be used to establish behaviour patterns and improve maintenance. This requires a welldefined framework that can guide the long-term roadmap front-end solutions for this to function.

In addition, cities need strategic interventions to help them move from 'businessas-usual' to a 'transformative' mindset. Strategic renovation works on "early adopter" buildings, chosen for their replicability and scalability, could be brought forward. Looking to increase the exponential impact of deep renovations, some works could inspire other urban areas to activate the same process. The EPBD encourages MS to carry out energy efficiency renovations by adopting a costeffectiveness or disruptive perspective. Experience shows that the range of costoptimal interventions includes envelope renovation, which is also quite representative and can help inspire confidence among stakeholders involved in building renovations. It can also be seen as a first step in developing renovation guidelines based on these experiences, in other words, a digital repository or 'library' of standardised solutions to be adopted during similar renovation processes (Wright, 2018). In this regard, authors such as Delmastro, Mutani, and Corgnati (2016) proposed defining building archetypes (Reference Buildings) as a first step to identify buildings in compelling need of renovation. This approach could be supported by the strategic instrument previously proposed as part of BRP tool. It should also provide an estimation of the expected energy savings after façade renovations as starting point, and wider benefits, such as those related to health, safety and air quality, for the entire building.

Over recent years, there are new trends in buildings towards a more user-centred design (Morton, Bull, Reeves, \& Preston, 2019). Research shows that improving and broadening user engagement has the potential to foster more action acceptance and impact (Morton et al., 2019). This should be seen as another strategy towards promoting deep renovations, since the influence that users' behaviour has on the energy consumption of buildings has been proved (Fabbri, de Groote, \& Rapf, 
2016). Therefore, user engagement can be a key issue for better building performance after well-designed renovations, together with the increase in indoor air quality. Users should be considered and informed about how higher comfort levels and well-being can improve their health with user-friendly tools. As a result, usercentred designs could support renovation works and increase the renovation rate. Furthermore, renovation processes that embrace building users could arrive at innovative solutions, such as new technologies that enable a better interaction of buildings and their users by adapting building operations to their needs. Therefore, user-centred design can also be a way to promote innovation in the building sector, while the building's energy efficiency and overall performance are improved.

Besides users, new strategies should be considered to guide renovation processes through co-created methodologies capable of including all stakeholders involved in building renovation. Co-creation can be used to refer to an act of collective creativity, where designers and other stakeholders work together in the design process, favouring desired changes to occur (Paone \& Bacher, 2018). By adopting a bottomup approach, supported by new technologies (e.g. ICT solutions) and smart features, co-creation processes could be applied to overcome some constraints identified in building management and renovation. To reduce subjectivity, for instance, methods such as the Analytical Hierarchy Process could be used to develop a Decision Support System that embodies stakeholders' relative preferences of multiple key criteria (functionality, cost, aesthetics, etc.). Gamification mechanisms could also be applied to facilitate renovation processes because they can increase stakeholders' interest. Since gamification can be an effective way for reducing energy consumption (Sanders \& Stappers, 2008), this could be used to overcome the lack of knowledge and awareness, another barrier that practitioners usually mention. Ultimately engaging all relevant stakeholders through such participative experiences seems an effective way of ensuring acceptance of measures adopted to achieve energy efficiency and quality targets.

Given that policies need to be accelerated for climate action and to transition to a sustainable built environment, several strategies should be explored. By identifying intervention cases, target-oriented actions could be adopted and work on the building stock phased to scale up its deep renovation. The new BRP's attempt to integrate and interlink building information and a roadmap seems to be a good starting point. Prioritising building façade interventions can be proposed as a possible trigger for promoting building interventions, with a view to seeking replicable best practices. Innovative measures on existing buildings and actions adopted for new synergies within projects and stakeholders have the potential to encourage other buildings and urban areas to adopt a similar approach. By taking advantage of experimental actions, existing buildings' renovations can be approached differently to increase effectiveness and stakeholder engagement. Practitioners and decisionmakers would benefit from the key role that new technological solutions can play in building management towards a systemic transformation of the construction sector (Volt \& Dorizas, 2018) and the improvement of the built environment. 


\subsection{Conclusion}

The deep renovation of buildings that are currently in a bad condition needs to be accelerated to avoid the enormous damage that problems in the building stock can cause on the environment, and to increase occupants' well-being. Two main paths can be identified to successfully manage the building stock while guaranteeing its renovation: (a) developing appropriate technologies to collect and process relevant data; and (b) assessing buildings by using adequate rating systems (e.g. energy performance, building condition, etc.). Additionally, the use of ICTs and other technologies during renovation can improve the decision-making process, guide the design of retrofitting solutions, and maximise environmental and social benefits. The successful implementation of technology and the use of innovative tools require appropriate actions, strategies and approaches.

Based on current regulations and plans, there is an agreement on the "big picture" of building stock management issues, and the needed transformation of the built environment. However, the transition to a sustainable built environment has so far been slow and we are far from achieving the objectives. In an attempt to accelerate this transformation, new tools and strategies can be applied to the building stock. Our shared reflections on how to improve the effectiveness of the measures adopted and on how to trigger the renovation of the building stock highlight more ambitious approaches, and innovative strategies and actions. Tailored rating systems and assessment tools can help improve renovations and even prioritise actions. Regular assessments performed during the operation stage of buildings also prevent building users and other people from being endangered. Therefore, both exhaustive and detailed diagnoses of the condition and performance of existing buildings are needed as a starting point to design customised interventions and increase the building sector's competitiveness.

The strategic measures put forward in this chapter include focusing efforts on building façade actions. This is because we encourage taking advantage of the impact that actions on this building element can have, both on user comfort and on the city environment, as it is also a determining factor in the energy performance of the buildings.

Building management supported by technology could guide the building transformation processes, thus enabling control of a pressing stakeholder demand: budget control during renovation works. As the transformation needs to be accelerated, further studies are needed on how the impact of these actions could be enhanced by adopting more ambitious approaches. One action has been identified here as the most promising: implementing restorative measures for renovated buildings. For instance, introducing the restorative perspective into new frameworks to evaluate existing buildings would enable us to estimate and consolidate the potential of renovated buildings.

Optimising processes that are part of the renovation of the building stock requires changes in cities led by a more ambitious vision to curb climate change and promote a regenerative built environment. Cities with resilient buildings and restored spaces 
will become more liveable, environmentally friendly and able to offer improvements in users' health and productivity.

\section{References}

Bhamra, A. S. (2015). Resilience framework for measuring development. In United Nation Brief for GSDR 2015. https://sustainabledevelopment.un.org/content/documents/642997Bhamra-Resilience\%20Framework\%20For\%20Measuring\%20Development.pdf. Accessed 28 Oct 2020.

Bortolini, R., \& Forcada, N. (2020). Operational performance indicators and causality analysis for non-residential buildings. Informes de la Construcción, 72, 333. https://doi.org/10.3989/ ic. 67792

BUILD UP. (2019). OVERVIEW | Socioeconomic and technical approaches to building stock renovation. https://www.buildup.eu/en/node/58540. Accessed 28 Oct 2020.

Chalmers, P. (2014). Climate change: Implications for buildings. http://bpie.eu/wp-content/ uploads/2015/10/Template_AR5_-_Buildings_v10_-_Web_Pages.pdf. Accessed 29 June 2020.

Craft, W., Ding, L., Prasad, D., Partridge, L., \& Else, D. (2017). Development of a regenerative design model for building retrofits. Procedia Engineering, 180, 658-668. https://doi. org/10.1016/j.proeng.2017.04.225

Delmastro, C., Mutani, G., \& Corgnati, S. P. (2016). A supporting method for selecting costoptimal energy retrofit policies for residential buildings at the urban scale. Energy Policy, 99, 42-56. https://doi.org/10.1016/j.enpol.2016.09.051

ENVISION. (2015). ENVISION-EmpoweriNg(European) SME business model InnovatiON. http:// www.envisionproject.eu/. Accessed 29 June 2020.

EuroACE. (2018). A guide to the implementation of the amended Energy performance of buildings directive (EPBD) 2018. https://euroace.org/wp-content/uploads/2018/11/EuroACE-Guide-toEPBD-Implementation-web-version.pdf. Accessed 29 June 2020.

EuroACE. (2020). Making the EU renovation wave a success. https://www.buildup.eu/sites/default/ files/content/making_the_eu_reno_wave_a_success_dft_final_april_2020.pdf. Accessed 29 June 2020.

European Commission. (2011). European construction sector observatory. https://ec.europa.eu/ growth/sectors/construction/observatory_en. Accessed 29 June 2020.

European Commission. (2016). The roadmap for transforming the EU into a competitive, lowcarbon economy by 2050. https://ec.europa.eu/clima/sites/clima/files/2050_roadmap_en.pdf. Accessed 26 Oct 2020.

European Commission. (2018). Directive (EU) 2018/844 of the European Parliament and of the council of 30 May 2018. Official Journal of the European Union. https://eur-lex.europa.eu/ legal-content/EN/TXT/PDF/?uri=CELEX:32018L0844\&from=ES. Accessed 29 June 2020.

European Commission. (2019). Improving energy and resource efficiency. https://www.buildup. eu/sites/default/files/content/ecso_ar_to3_november_2018.pdf. Accessed 29 June 2020.

Fabbri, M., de Groote, M., \& Rapf, O. (2016). Building Renovation Passports. Customised roadmaps towards deep renovation and better homes. http://bpie.eu/wp-content/uploads/2017/01/ Building-Passport-Report_2nd-edition.pdf. Accessed 29 June 2020.

González, A. G., Zotano, M. Á. G., Swan, W., Bouillard, P., \& Elkadi, H. (2017). Maturity matrix assessment: Evaluation of energy efficiency strategies in Brussels historic residential stock. Energy Procedia, 111, 407-416. https://doi.org/10.1016/j.egypro.2017.03.202 
Historic England. (2017). BIM for heritage: Developing a historic building information model. Swindon, UK: Historic England. https://historicengland.org.uk/images-books/publications/ bim-for-heritage/heag-154-bim-for-heritage/. Accessed 29 June 2020.

Huovila, A., Bosch, P., \& Airaksinen, M. (2019). Comparative analysis of standardized indicators for smart sustainable cities: What indicators and standards to use and when? Cities, 89, 141-153. https://doi.org/10.1016/j.cities.2019.01.029

InBetween. (2017). InBetween project. https://www.inbetween-project.eu/. Accessed 29 June 2020.

Kolokotsa, D., Diakaki, C., Grigoroudis, E., Stavrakakis, G., \& Kalaitzakis, K. (2009). Decision support methodologies on the energy efficiency and energy management in buildings. Advances in Building Energy Research, 3, 121-146. https://doi.org/10.3763/aber.2009.0305

Mahmoud, S., Zayed, T., \& Fahmy, M. (2019). Development of sustainability assessment tool for existing buildings. Sustainable Cities and Society, 44, 99-119. https://doi.org/10.1016/j. scs.2018.09.024

MOBISTYLE. (2016). MOBISTYLE project. https://www.mobistyle-project.eu/. Accessed 29 June 2020.

Morton, A., Bull, R., Reeves, A. and Preston, S. (2019). ICT for sustainability: Reflecting on the role of ICT to enhance communication and empowerment of building users. Smart and Sustainable Communities, 5, 855-863. https://www.eceee.org/library/conference_proceedings/ eceee_Summer_Studies/2019/5-smart-and-sustainable-communities/ict-for-sustainabilityreflecting-on-the-role-of-ict-to-enhance-communication-and-empowerment-of-buildingusers/. Accessed 29 June 2020.

Nielsen, A. N., Jensen, R. L., Larsen, T. S., \& Nissen, S. B. (2016). Early stage decision support for sustainable building renovation - A review. Building and Environment, 103, 165-181. https:// doi.org/10.1016/j.buildenv.2016.04.009

Olsson, S., Malmqvist, T., \& Glaumann, M. (2016). An approach towards sustainable renovation A tool for decision support in early project stages. Building and Environment, 106, 20-32. https://doi.org/10.1016/j.buildenv.2016.06.016

Paone, A., \& Bacher, J. P. (2018). The impact of building occupant behavior on energy efficiency and methods to influence it: A review of the state of the art. Energies, 11(4), 953. https://doi. org/10.3390/en 11040953

Pombo, O., Rivela, B., \& Neila, J. (2016). The challenge of sustainable building renovation: Assessment of current criteria and future outlook. Journal of Cleaner Production, 123, 88-100. Available from: https://doi.org/10.1016/j.jclepro.2015.06.137.

RESTORE. (2018). Sustainability, restorative to regenerative. https://www.eurestore.eu/wpcontent/uploads/2018/04/Sustainability-Restorative-to-Regenerative.pdf. Accessed 29 June 2020.

RESTORE. (2020). Regenerative construction and operation. https://www.eurestore.eu/wpcontent/uploads/2019/07/RESTORE-WG3-Booklet.pdf. Accessed 29 June 2020.

Sanders, E. B. N., \& Stappers, P. J. (2008). Co-creation and the new landscapes of design. Co-design, 4(1), 5-18. https://doi.org/10.1080/15710880701875068

Sesana, M. M., Rivallain, M., \& Salvalai, G. (2020). Overview of the available knowledge for the data model definition of a building renovation passport for non-residential buildings: The ALDREN project experience. Sustainability, 12, 642. https://doi.org/10.3390/su12020642

Sonetti, G., Naboni, E., \& Brown, M. (2018). Exploring the potentials of ICT tools for humancentric regenerative design. Sustainability, 10, 1217. https://doi.org/10.3390/su10041217

Thuvander, L., Femenías, P., Mjörnell, K., \& Meiling, P. (2012). Unveiling the process of sustainable renovation. Sustainability, 4, 1188-1213. https://doi.org/10.3390/su4061188

Volt, J., \& Dorizas, V. (2018). Policy innovation for building renovation. http://bpie.eu/wp-content/ uploads/2019/01/BPIX-Briefing__Final-1.pdf. Accessed 29 June 2020.

Wright, W. (2018). (CT2) existing buildings \& systems: Status in June 2018. Depression and Anxiety, 35, 488-489. https://doi.org/10.1002/da.22780 
Open Access This chapter is licensed under the terms of the Creative Commons Attribution 4.0 International License (http://creativecommons.org/licenses/by/4.0/), which permits use, sharing, adaptation, distribution and reproduction in any medium or format, as long as you give appropriate credit to the original author(s) and the source, provide a link to the Creative Commons license and indicate if changes were made.

The images or other third party material in this chapter are included in the chapter's Creative Commons license, unless indicated otherwise in a credit line to the material. If material is not included in the chapter's Creative Commons license and your intended use is not permitted by statutory regulation or exceeds the permitted use, you will need to obtain permission directly from the copyright holder. 